\title{
Outcome of Vesico Ureteral Reflux in Children (VUR) and Idiopathic Hypercalciuria (IHC) associated with Urinary Tract Infection (UTI) in Indian Children
}

\author{
Gupta A.K. ${ }^{1}$, Kumar V. ${ }^{2}$, Wilson C.G. ${ }^{3}$, Tomar R.P.S. ${ }^{4}$, Sahu S. ${ }^{5}$ \\ ${ }^{1}$ Dr. (Lt Col) Ashish Kumar Gupta, Paediatrician, Military Hospital, Secunderabad, ${ }^{2}$ Dr. Vinay Kumar, Registrar, Rainbow \\ Children Hospital, Banjara Hills, Hyderabad, ${ }^{3}$ Dr. (Col) C.G. Wilson, Academic Head (DNB), Rainbow Children Hospital, \\ Banjara Hills, Hyderabad, ${ }^{4}$ Dr. (Col) R.P.S. Tomar, Advisor (Paediatrics \& Neonatology), Military Hospital Secunderabad, ${ }^{5}$ Dr. \\ Sonam Sahu, Medical Officer, Regional Centre ECHS, Secunderabad.
}

Corresponding Author: Dr. (Lt Col) Ashish Kumar Gupta, Paediatrician, Military Hospital, Secunderabad, Telangana. India. E-mail: drakg.acad@gmail.com

\begin{abstract}
Background: Paediatric UTI associated with predisposing factors like VUR and IHC causes severe damage to renal tissues resulting in renal scars. Material and Methods: This prospective observational study was conducted from August 2017 to January 2019 in teaching military hospital and tertiary care corporate hospital was done to analyse and quantify the effects of these co-morbidities in Indian children with UTI. Results: A total 405 children of UTI were studied. 55 children (13.58\%) had VUR being predominantly in the age group of $1-36$ months $(74.54 \%)$ with majority males $(58.55 \%) .4$ children $(0.98 \%)$ had IHC. 346 children or $85.43 \%$ of sample size did not show any signs of VUR or IHC. 17 male children (56.66\%) and 13 female children (43.33\%) had bilateral VUR. Out of the 55 children with VUR, 26 (47.27\%) developed renal scars. Conclusion: Medical management was successful in resolution of $27 \%$ of cases. All the 8 cases with Grade V VUR did not improve and required surgery. All the cases of IHC resolved spontaneously on conservative management.
\end{abstract}

Keywords: Hypercalciuria, Pyelonephritis, Renal scars, Urinary tract infection, Vesico-ureteral reflux

\section{Background}

Urinary Tract infection (UTI) is one of the most frequent diseases in paediatric age group causing long term morbidity. Febrile UTI is known to affect the kidneys causing pyelonephritis and renal scars [1].

This is especially true for the growing young vulnerable renal tissues during initial years of life. Anomalies of urinary tract such as vesico-ureteric reflux (VUR) and idiopathic hypercalciuria (IHC) are known risk factors for recurrent UTI and the risk is correlated with the severity.

VUR can be an isolated finding and called primary reflux or can be associated with other urological anomalies such as posterior urethral valves or ureterocoele and referred to as secondary reflux. Association of VUR with UTI was shown to be prerequisite for renal scarring by classical study published by Ranslay and Risden in 1978 [2]. VUR with secondary bacterial infection of renal parenchyma leads to acute inflammatory reaction in the renal tissue.

Manuscript received: $\mathbf{1 0}^{\text {th }}$ December 2019

Reviewed: $\mathbf{2 0}^{\text {th }}$ December 2019

Author Corrected: $\mathbf{2 6}^{\text {th }}$ December 2019

Accepted for Publication: 31 ${ }^{\text {st }}$ December 2019
This inflammation is mediated by cytokine release, resulting in focal parenchymal ischaemia and ultimately scarring. The extent of renal damage after a febrile infection depends on bacterial and host factors that mediate the response to infection. Late sequelae of renal scarring such as hypertension, proteinuria, or even chronic renal failure can be seen in the second or third decade of life [3].

Non-anatomic problems such as hypercalciuria as a cause of UTI is increasingly being recognised in recent years. Idiopathic hypercalciuria (IHC) is one of the most common causes of urolithiasis in children. It can also present with myriad of symptoms such as haematuria, voiding dysfunction, flank pain, nephrolithiasis and decreased bone mineral density [4].

In the present study were trying to determine the association of VUR and idiopathic hypercalciuria with UTI in Indian children and the outcomes by following the cases over the study period. There are no similar studies in Indian children, as most studies have focussed only on prevalence patterns and clinical profiles. 
Original Research Article

\section{Materials and Methods}

Setting: A corporate tertiary care hospital and an army teaching hospital.

Ethical consideration \& permission: The study was approved by the Ethical committees of both hospitals. All the cases of UTI in the age group of 01 month to 12 years reporting to both hospitals during the study period were included after a written informed consent was taken from each parent before inclusion in this study.

Type of study: Prospective cohort observational study.

Duration: 18 months from Aug 2017 to January 2019.

\section{Inclusion criteria}

(a) Children aged 01 month -12 years with UTI.

(b) Parents willing to provide written informed consent.

\section{Exclusion criteria}

1. Children with antenatally diagnosed renal disease.

2. Children with chronic diseases, on diuretic or corticosteroid/ immunosuppressants.

3. Children with pelviureteric junction abnormalities.

4. Patients who were detected to have secondary hypercalciuria.

5. Children aged below 01 month and more than 12 years.

Methodology: Paediatrician/ ER physician assessed all children with UTI at the time of admission, at the time of discharge and during follow up. A predesigned structured proforma was filled with demographic, prehospital data, clinical history and examination details to ascertain eligibility for inclusion in the study. Criteria for UTI was evidence of pyuria in addition to positive culture results. Urine analysis was done in all suspected cases to detect pyuria. It was taken as 5 WBCs in centrifuged urine sample or $10 \mathrm{WBCs}$ in uncentrifuged urine with at-least 01 -gram negative rod in 10 oil immersion fields on gram staining of uncentrifuged urine. On urine culture the appropriate threshold to consider bacteriuria significant was taken as $50000 \mathrm{CFU} / \mathrm{ml}$ of a single urinary pathogen [5].

In all cases ultrasonography (USG) of abdomen was done for kidney and bladder assessment including calyceal dilatation and pelvic findings. Contrast voiding cysto-urethrogram (VCUG) was performed for analysing anatomical information and VUR and to rule out malformations such as duplex collecting system, ectopic ureter, para-ureteral bladder diverticulum, bladder outlet obstruction in boys and spinning top urethra in girls. Di-Mercapto-Succinic Acid (DMSA) scintigraphy was done to detect renal scars, abscess, cysts and duplex kidney. Diehthylene Triamine Penta-acetic Acid (DTPA) scan was performed to detect percentage of function of each kidney. VUR severity was graded according to the International Reflux Study Classification into grades I-V based on appearance of the urinary tract on a contrast voiding cystourethrogram (VCUG) [4].

Idiopathic hypercalciuria was defined as patients with normal calcemia (in the absence of conditions or drugs that may cause hypercalciuria) having urine calcium to creatinine ratio $>0.8$ in children $0-6$ months; $>0.6$ in children aged $7-12$ months old; $>0.5$ in the age 12-24 month and $>0.2$ in patients older than 2 years (measuring fasting urine sample) [6]. The hematological, pathological, microbiological and radiological findings were obtained from the case records and filled in the proforma for further assessment.

The patients in the study with VUR and IHC were observed for a period of 01 year to observe for resolution of abnormalities. VUR was followed up by ultrasound at discharge, 6 months and at 1 year. A repeat VCUG was done at 1 year to look for residual dilatation. IHC was followed at same intervals with urine calcium-creatinine ratios. Medical management was given to all the patients to keep the urine sterile with antibiotic prophylaxis for at-least 6 months and follow up. Surgical management was offered to patients with high grade VUR which did not resolve with medical management.

Sample size calculation: Assuming a level $12 \%$ of children with UTI develop VUR, number of children required is minimum of 160 children. The estimate is derived by using the following formula: $N=Z^{2} \mathrm{P}(1-\mathrm{P}) / £^{2}$ where $\mathrm{Z}^{2}$ factor corresponds to Type I error and was taken as 1.96 with 2-sided test, $\mathrm{P}$ is \% of children with UTI developing VUR (assumed as $12 \%$ from hospital data) and $£^{2}$ is the level of precision (usually taken as $5 \%$ ). 
Original Research Article

Data Collection: In the present study, a total of 508 patients from both hospitals were screened for enrolment in the study. 49 patients had to be excluded due to pre-existing anomalies or the parent's unwilling for study. Further 54 patients were either lost to follow up or refused continued investigations.

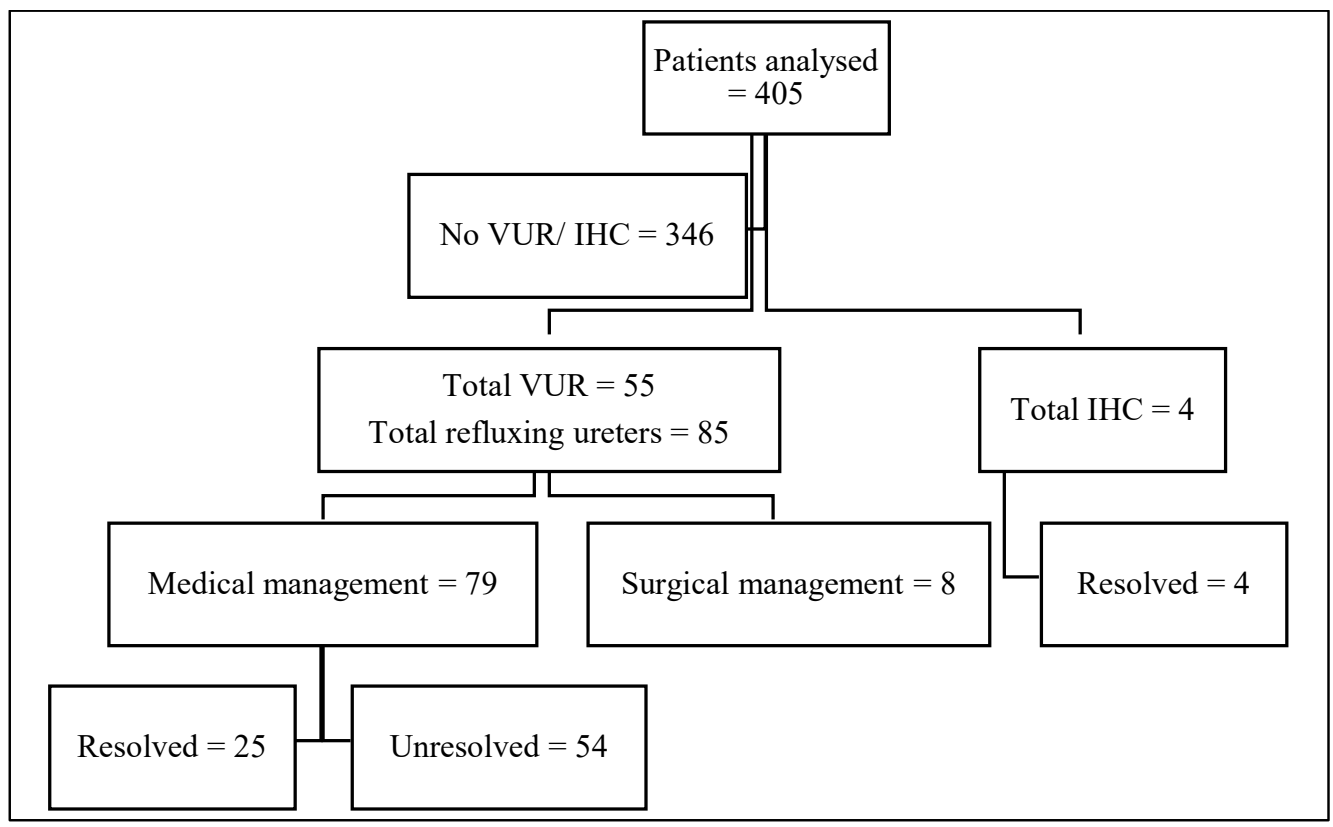

Fig-1: Study design of the present study.

Statistical Analysis: The data for study was collected in pre-designed study proforma and was verified for completeness and consistency before transferring into MS Excel for further analysis. The continuous variables were expressed as mean and standard deviation (SD), median and inter-quartile range (IQR) and frequency distribution for categorical variables.

Nonparametric tests like Man-Whitney Median tests, Chi-Square and Fishers exact test are applied when necessary. Subgroup analysis is applied between various factors and outcome measures. p-value of $<0.05$ was considered statistically significant. Data was analysed using SSPS (21 $1^{\text {th }}$ Version).

\section{Results}

A total of 223 males and 182 females had UTI during the study period (M:F ratio 1.22:1) with UTI were analysed after excluding those not willing to participate, having congenital structural anomalies, not willing to give consent and lost to follow-up. Majority of the patients $270(66.7 \%)$ were in the age group of 1-36 months. This group also exhibited male predominance.

Table-1: Cases of VUR and IHC in study group $(N=403)$.

\begin{tabular}{|c|c|c|c|}
\hline Conditions & Total no & Male no (\%) & Female no (\%) \\
\hline VUR & 55 & $29 / 55(52.72)$ & $26 / 55(47.27)$ \\
\hline IHC & 4 & $2 / 4(50.0)$ & $2 / 4(50.0)$ \\
\hline Without VUR/IHC & 346 & $191 / 346(55.20)$ & $153 / 344(44.21)$ \\
\hline
\end{tabular}

A total of 55 children were found to have VUR with 4 children showing evidence of idiopathic hypercalciuria. Out of which 55 children who had VUR, a majority of 41 children (74.54\%) were again in the age group of 1-36 months with male predominance $(58.55 \%)$.

Gender ratio of all VUR cases was marginally skewed towards males (1.11:1). IHC was found to be distributed evenly amongst both genders with 2 cases each. 346 children or $85.43 \%$ of sample size did not show any signs of VUR or IHC (Table 1).

Table-2: Prevalence of unilateral and bilateral VUR according to gender $(\mathrm{N}=55)$ and association with renal scars $(\mathbf{N}=\mathbf{2 6})$. 
Original Research Article

\begin{tabular}{|c|c|c|}
\hline Conditions & Males number (\%) & Females number (\%) \\
\hline VUR - Bilateral (30) & $17 / 30(56.66)$ & $13 / 30(43.33)$ \\
\hline VUR - Unilateral (25) & $13 / 25(52.00)$ & $12 / 25(48.00)$ \\
\hline Renal Scars (26/55) & $14 / 26(53.84)$ & $12 / 26(46.15)$ \\
\hline
\end{tabular}

17 male children (56.66\%) and 13 female children (43.33\%) had bilateral VUR. Thus, there were 85 refluxing ureters (47 in males and 38 in females) with M:F ratio of 1.27:1. Among the 17 male children, 4 children (23.52\%) had different grades of VUR on either side compared to $15.38 \%$ (2 out of 13) in females. Out of the 55 children with VUR, 26 (47.27\%) developed renal scars. Amongst these, 14 out of 26 male children (48.27\%) and 12 out of 26 female children (46.15\%) had renal scars. There was no statistical significance between the different genders on the propensity to develop renal scars due to VUR with UTI (Table 2).

Table-3: Cases of hydronephrosis associated VUR and IHC:

\begin{tabular}{|c|c|c|c|c|}
\hline Hydronephrosis & Unilateral (\%) & Bilateral (\%) & Total no (\%) & Normal \\
\hline VUR & $13 / 55(23.63)$ & $10 / 55(18.18)$ & $23 / 55(41.81)$ & $32 / 55(58.18)$ \\
\hline IHC & $1 / 4(25.00)$ & 0 & $1 / 4(25.00)$ & $3 / 4(75.00)$ \\
\hline
\end{tabular}

A significant number of 23 children (41.81\%) had also developed hydronephrosis in association with VUR in UTI. Majority of the cases of hydronephrosis associated with milder grades of VUR resolved spontaneously (Table 3).

Table-4: Outcome in number of refluxing ureters $(\mathrm{N}=85)$ :

\begin{tabular}{|c|c|c|}
\hline Grades of VUR & Improved No. (\%) & Not Improved No. (\%) \\
\hline Grade I & - & - \\
\hline Grade II & $11(29.72)$ & $14(70)$ \\
\hline Grade III & $6(30)$ & $14(77.77)$ \\
\hline Grade IV & $4(22.22)$ & $8(80)$ \\
\hline Grade V & $2(20)$ & $87)$ \\
\hline
\end{tabular}

All children with different grades were given medical treatment. Management of VUR with prophylactic antibiotics resulted in resolution of $27 \%$ of cases. The proportion of resolved cases decreased progressively with increasing grades of VUR. Only $20 \%$ of children with Grade V VUR and 22.2\% with Grade IV VUR improved. All the 8 cases with Grade V VUR who did not improve underwent surgery (Table 4).

\section{Discussion}

UTI in children is a commonly encountered problem in pediatric practice. Anatomical malformations such as VUR and non-anatomical conditions such as hypercalciuria in UTI are usually associated with more severe manifestations including recurrent disease and reflux nephropathy. The association of VUR with nephropathy is paradoxical. While most children with renal lesions do not have VUR, numerous studies show a close relationship between VUR and nephropathy.

The higher the grade, the greater the risk of damage and loss of renal function. Prognosis is worst when reflux nephropathy (RN) is bilateral. The importance of VUR therefore seems to be its association with worse outcomes.
Pyelonephritic damage leading to renal failure in the absence of VUR has rarely been reported. The primary goal of treatment with reflux is preventing renal injury, symptomatic pyelonephritis and other complications of reflux. Medical therapy is based on the principle that reflux often resolves with time, and antibiotics maintain urine sterility and prevent infections while the patient awaits spontaneous resolution.

The basis of surgical therapy is that, in select situations, ongoing vesico-ureteral reflux has caused or has a significant potential for causing renal injury or other reflux related complications and elimination of the reflux will minimise their likelihood [7].

The incidence of VUR and resultant renal damage and scars vary widely in different populations, regions and period of study. The International Reflux Study in Europe gave a conservative figure of $5.9 \%$ new renal scarring in a study of 
Original Research Article

312 children [8]. However, subsequent studies done in Sweden found the incidence to be higher at 11.7 to $26 \%$ $[9,10]$. Studies done in Italy in primary VUR cases revealed scarring upto 67 to $85 \%$ in individual refluxing kidneys or units $[11,12]$. In multicentric RIVUR study done in children with primary VUR in US, incidence of $9.5 \%$ renal scarring was noticed in 607 children [13].

Studies done in Africa in Sudanese children noted higher incidence varying from $54.46 \%$ to $61.5 \%[14,15]$. Amongst developed Asian countries, lower incidence was noted by Yilmag et al in Turkey at 19.4\%, Goldman et al in Israel at $19 \%$ and Howard et al in in Chinese boys (28\%) and girls $(11 \%)[16,17,18]$. In a South Korean study by Lee et al, the incidence noted was $47.9 \%$ in 48 cases of VUR [19]. A similar incidence of $41 \%$ was found by Al-Ibrahim et al in Saudi children [20]. Older studies done in North India by Menon et al revealed a higher prevalence of renal scarring $(62 \%)$ in VUR patients with UTI [21].

The present study enrolled patients with UTI (culture positive) in the age group of 1 month to 12 years and 405 children fulfilling the inclusion criteria were evaluated. A total of 55 children were found to have VUR (13.58\%) with male predominance (1.11:1). No statistical significance was seen in difference between both the genders. Of these, 30 children had bilateral VUR and 25 unilateral VUR making a total of 85 refluxing ureters. This was in contrast to studies done by Lama et al and Caione et al which had higher proportion of unilateral VUR $[10,11]$. Out of the 55 children with VUR, 26 (47.27\%) developed renal scars. This incidence was comparable to the study done by Lee et al [19] and Al-Ibrahim et al [20] and was lower than the older Indian study [21] which could be attributed to better screening and treating facilities at present. The prevalence was significantly higher than other Asian ethnicities as observed by Yilmaz et al [16], Goldman et al [17] and RG Howard et al [18].

Renal scarring as an outcome was more predominant in findings described by Nacaroglu HT el al (54.46\%) [14] and Ali ET el al (61.53\%) in Sudanese children [15] and those described in Italian studies by Lama et al and Caione et al $[11,12]$. Incidence of hydronephrosis was found to be present in 23 out of 55 children $(41.81 \%)$ in children with VUR. A significant number of children had differential renal function as a consequence of scarring associated with VUR. The higher incidence of renal scars in VUR with UTI in Indian population should prompt immediate treatment in identified cases to prevent the consequent damage. The prevalence was also in higher proportion in younger children and male gender which should be targeted for more intensive evaluations. Idiopathic hypercalciuria characterized with increased excretion of calcium ions in urine in spite of normal serum calcium levels [22], is a condition commonly associated with urinary symptoms [23]. It can present with nonspecific urinary symptoms such as frequency, occasional dysuria, non-nephrotic range proteinuria [23] and is the most common anomaly associated with isolated hematuria and urolithiasis [24,25]. Idiopathic hypercalciuria has been shown to be important risk factor for recurrent UTI [26] and if present with VUR it correlates with more severe grades of VUR [27].

The prevalence can be upto $10 \%$ and depends on geographical region, climate, nutrition and genetic factors. Adequate treatment prevents stone formation and preserves the bone mineral density in patients [27]. Management is usually with liberal oral fluids with salt restriction. In cases with gross hematuria or persistent dysuria, oral diuretic (hydrochlorothiazide) therapy may be required for resolution of symptoms [28]. As it is associated with recurrent UTI and severe grades of VUR, treatment and close monitoring for resolution of hypercalciuria is warranted. Incidence of idiopathic hypercalciuria was found to be negligible in the present study at 4 out of 405 cases $(0.98 \%)$ of UTI which was statistically much lower than reported earlier in other populations at $16.29 \%, 16 \%$ and $30 \%$ by Balestracci A et al [6], Nacaroglu HT et al [14], and Sadeghi-Bojd S et al [26] respectively. Moreover, the spontaneous resolution of hypercalciuria without the dreaded complications portends a benign profile in Indian children. The causes of low incidence could be possibly dietary or nutritional deficiencies and needs to be further investigated in a larger controlled study.

With medical management there was improvement in 25 out of 85 refluxing ureters $(29.41 \%)$ and non-resolution in remaining 60 cases. The resolution of symptoms improved in lower grades of VUR with maximal resolution in Grade II VUR patients. Surgical management was only required in 8 cases with grade V VUR. No fresh scarring was noticed in surgically managed cases in the duration of study period. All 4 cases of IHC resolved over next 1 year without complications. The major limitation of the study was limited time period of observation, so complications and their resolution could be observed for a relatively smaller period of time. A multicentric pan India study is needed to delineate the long-term effects of VUR and IHC associated with UTI in paediatric patients. Antenatally detected renal diseases were not taken into account as it needs a separate criterion for monitoring and follow up. Also, the patients lost to follow up and those who refused consent could not be followed up.

\section{Conclusion}

The incidence of renal scarring in VUR with UTI in Indian children was comparable to other Asian populations at $47.27 \%$. The prevalence of renal damage has improved 
compared to older studies most likely due to improved healthcare facilities, however it remains significantly higher compared to developed countries.

Medical management was sufficient for resolution in a significant number of cases of low grade VUR (I-III).

Majority of high grade VUR did not resolve over the observation period of 18 months, however surgical management was required only in significant non-resolving grade V VUR. A total of $27 \%$ refluxing ureters resolved with medical management alone. The prevalence of idiopathic hypercalciuria was found to be inappreciable numbers $(0.98 \%)$. All cases resolved over the period of study without any significant complications.

\section{What this study adds to existing knowledge?}

Incidence of renal scarring consequent to VUR in UTI was noted to be $47.27 \%$, with resolution in approximately one fourth of cases by medical management alone.

The incidence is reducing compared to older Indian studies most likely consequent to improved healthcare facilities. The association of Idiopathic hypercalciuria with UTI was found to be negligible at $0.98 \%$ and complete resolution of all cases was achieved with conservative treatment.

\section{Author's contributions}

CGW, VK conceived the study. VK, AKG, SS examined the patients, collected the data. AKG, CGW analysed the data and drafted manuscript. RPS revised the manuscript. All the authors read and approved the final manuscript.

Funding: No funding sources

Conflict of interest: None declared

Ethical Approval: This study was approved by the Institutional Ethics Committee.

\section{Reference}

1. Shaikh N, Hoberman A, Keren R, Gotman N, Docimo SG, Maathews R, et al. Recurrent Urinary Tract Infections in Children with Bladder and Bowel Dysfunction. Pediatr. 2016;137(1):e20152982. doi: https://doi.org/10.1542/peds. 2015-2982.

2. Blumenthal I. Vesicoureteric reflux and urinary tract infection in children. Postgra Med J. 2006;82(963):31-35. doi: http://dx.doi.org/10.1136/pgmj.2005.036327.

3. Garcia RM, Kirsch A. Urinary tract infection in the setting of vesicoureteral reflux. F1000Research. 2016;5:1552. doi: https://doi.org/10.12688/f1000research. 8390.1 .
4. Kliegman RM, Behrman RE, Jenson HB, Stanton BM. Urinary Tract Infections. 20/e. Nelson Textbook of Pediatrics E-Book. Elsevier Health Sciences; Philadelphia 2016; (2): pp 2556.

5. Subcommittee OU. Reaffirmation of AAP Clinical Practice Guideline: The Diagnosis and Management of the Initial Urinary Tract Infection in Febrile Infants and Young Children 2-24 Months of Age. Pediatr. 2016;138 (6):e20163026. doi: https://doi.org/10.1542/peds.20163026 .

6. Balestracci A, Meni Battaglia L, Toledo I, Martin SM, Wainsztein RE. Idiopathic hypercalciuria in children with urinary tract infection. Arch Argent Pediatr. 2014;112(5): 428-433. doi: http:// dx.doi.org/10. 5546/aap. 2014. 428.

7. Elder JS, Peters CA, Arant BS, Ewalt DH, Hawtrey CE, Hurwitz RS, et al. Pediatric Vesicoureteral Reflux Guidelines Panel summary report on the management of primary vesicoureteral reflux in children. J Urol. 1997;157 (5):1846-1851.

8. Olbing H., Claësson I., Ebel K.-D., Seppänen U., Smellie J.M., Tamminen-Möbius T., et al. Renal Scars and Parenchymal Thinning in Children with Vesicoureteral Reflux: A 5-Year Report of the International Reflux Study in Children (European Branch). J Urol. 1992 Nov 1;148(5 Part 2):1653-6. doi: https://doi.org/10.1016/S0022-5347 (17) $36995-1$.

9. Brandström Per, Nevéus Tryggve, Sixt Rune, Stokland Eira, Jodal Ulf, Hansson Sverker. The Swedish Reflux Trial in Children: IV. Renal Damage. J Urol. 2010;184(1): 292297. doi: https://doi.org/10.1016/j.juro. 2010.01. 060.

10. Swerkersson S, Jodal U, Sixt R, Stokland E, Hansson S. Relationship Among Vesicoureteral Reflux, Urinary Tract Infection and Renal Damage in Children. J Urol. 2007;178(2):647-651. doi: https://doi.org/10.1016/j.juro. 2007.04.004.

11. Caione P, Ciofetta G, Collura G, Morano S, Capozza N. Renal damage in vesico-ureteric reflux. BJU Int. 2004; 93 (4):591-595. doi: https://doi.org/10.1111/j.1464-410X. 2003. 04673.x.

12. Lama G, Russo M, De Rosa E, Mansi L, Piscitelli A, Luongo I, et al. Primary vesicoureteric reflux and renal damage in the first year of life. Pediatr Nephrol. 2000; 15 (3): 205-210. doi: https://doi.org/10.1007/s004670000455.

13. Mattoo TK, Chesney RW, Greenfield SP, Hoberman A, Keren R, Mathews R, et al. Renal Scarring in the Randomized Intervention for Children with Vesicoureteral 
Original Research Article

Reflux (RIVUR) Trial. CJASN. 2016;11(1):54-61. doi: https://doi.org/10.2215/CJN.05210515.

14. Nacaroglu HT, Demircin G, Bülbül M, Erdogan O, Akyüz SG, Caltik A. The association between urinary tract infection and idiopathic hypercalciuria in children. Ren Fail. 2013;35(3):327-332.

15. Ali E-TMA, Alfaki EM, Abdelraheem MB. Primary vesicoureteral reflux in Sudanese children. Saudi J Kid Dis Transpl. 2014;25(4):900-905. doi: https://doi.org/10.4103/ 1319-2442. 135212.

16. Yılmaz S, Özçakar ZB, Şükür EDK, Bulum B, Kavaz A, Elhan AH, et al. Vesicoureteral Reflux and Renal Scarring Risk in Children after the First Febrile Urinary Tract Infection. NEF. 2016;132(3):175-180. doi: https:// doi. org/ 10. 1159/000443536.

17. Goldman M, Bistritzer T, Horne T, Zoareft I, Aladjem M. The etiology of renal scars in infants with pyelonephritis and vesicoureteral reflux. Pediatr Nephrol. 2000; 14 (5): 385-388. doi: https://doi.org/10.1007/s0046700 50779.

18. Howard RG, Roebuck DJ, Yeung PA, Chan KW, Metreweli C. Vesicoureteric reflux and renal scarring in Chinese children. Br J Radiol. 2001;74(880):331-334. doi: https://doi.org/10.1259/bjr.74.880.740331.

19. Lee JH, Son CH, Lee MS, Park YS. Vesicoureteral reflux increases the risk of renal scars: a study of unilateral reflux. Pediatr Nephrol. 2006;21(9):1281-1284. doi: https://doi.org/10.1007/s00467-006-0147-x.

20. Al-Ibrahim AA, Girdharilal RD, Jalal MAC, Alghamdy AH, Ghazal YK. Urinary Tract Infection and Vesicoureteral Reflux in Saudi Children. Saudi J Kid Dis Transpl. 2002;13(1):24-28.

21. Menon P, Rao KLN, Bhattacharya A, Mahajan JK, Samujh R. Primary vesicoureteral reflux: progress of disease, somatic growth and renal parameters. Indian Pediatr. 2004;41(10):1025-1030.

22. Langman CB, Moore ES. Hypercalciuria in clinical pediatrics. A review. Clin Pediatr (Phila) 1984;23(3):135137. doi: https://doi.org/10.1177/000992288402300301.

23. Heiliczer JD, Canonigo BB, Bishof NA, Moore ES. Noncalculi urinary tract disorders secondary to idiopathic hypercalciuria in children. Pediatr Clin North Am. 1987; 34(3):711-718. doi: https://doi.org/10.1016/S0031-3955 (16) $36263-0$.

24. Letavernier E, Traxer O, Daudon M, Tligui M, HubertBrierre J, Guerrot D, et al. Determinants of osteopenia in male renal-stone-disease patients with idiopathic hypercalciuria. Clin J Am Soc Nephrol. 2011;6(5):11491154. doi: https://doi.org/10.2215/CJN.10191110.

25. Coe FL, Worcester EM, Evan AP. Idiopathic hypercalciuria and formation of calcium renal stones. Nat Rev Nephrol. 2016;12(9):519-533. doi: https://doi.org/ 10.1038/nrneph.2016.101.

26. Sadeghi-Bojd S, Hashemi M. Hypercalciuria and recurrent urinary tract infections among children in Zahedan, Iran. J Pak Med Assoc. 2008;58(11):624-626.

27. Mahyar A, Dalirani R, Ayazi P, Hamzehloo S, Moshiri SA, Khoshbakht Ahmadi $\mathrm{N}$, et al. The association of hypercalciuria and hyperuricosuria with vesicoureteral reflux in children. Clin Exp Nephrol. 2017;21(1):112-116. doi: https://doi.org/10.1007/s10157-016-1236-1.

28. Escribano J, Balaguer A, Pagone F, Feliu A, Roqué I Figuls M. Pharmacological interventions for preventing complications in idiopathic hypercalciuria. Cochrane Database Syst Rev. 2009;(1):CD004754. doi: https:// doi.org/ 10.1002/14651858.CD004754.pub2.

\section{How to cite this article?}

Gupta A.K, Kumar V, Wilson C.G, Tomar R.P.S, Sahu S. Outcome of Vesico Ureteral Reflux in Children (VUR) and Idiopathic Hypercalciuria (IHC) associated with Urinary Tract Infection (UTI) in Indian Children. Int J Pediatr Res.2019; 6(12): 613619.doi:10.17511/ijpr.2019.i12.05 